\title{
Entry points of nutrient arteries at risk during osteotomy of the lesser metatarsals: a fresh cadaveric study
}

\author{
Ichiro Tonogai ${ }^{1 *}$, Fumio Hayashi ${ }^{1}$, Yoshihiro $^{\text {Tsuruo }}{ }^{2}$ and Koichi Sairyo ${ }^{1}$
}

\begin{abstract}
Background: Osteotomies of the lesser (second to fourth) metatarsals are often used to correct forefoot deformities. However, certain areas of the lesser metatarsals where arteries may be prone to damage during surgery, and the resulting nonunion and delayed union could cause serious problems. This study sought to identify the nutrient arteries of the lesser metatarsals and to determine how osteotomy could injure these vessels.

Methods: Enhanced computed tomography scans of $21 \mathrm{ft}$ (male, $n=10$; female, $n=11$; mean age 78.6 years at the time of death) were assessed. Twenty-one lower limbs in 21 cadaveric specimens were injected with barium via the external iliac artery, and the points at which the nutrient arteries entered the lesser metatarsals were identified on axial and coronal images.

Results: Each nutrient artery entered the lateral or medial plantar aspect of the lesser metatarsal in the middle third (just proximal to the middle point of the metatarsal) or proximal third obliquely from a distal direction. The mean \pm standard deviation (SD) distances from the dorsal plane of the second, third, and fourth metatarsals to the point of entry of the nutrient artery in the axial plane were $8.2 \pm 1.5,7.6 \pm 1.2$, and $7.6 \pm 1.5 \mathrm{~mm}$, respectively. The mean \pm SD distances from the distal epiphysis to the point of entry of the nutrient artery into the second, third, and fourth metatarsals in the coronal plane were $3.3 \pm 1.1,3.1 \pm 1.0$, and $2.8 \pm 1.2 \mathrm{~mm}$, respectively. The mean $\pm \mathrm{SD}$ distances from the distal epiphysis to the point of entry of the nutrient artery into the second, third, and fourth metatarsals in the coronal plane were $46.0 \pm 5.2,40.9 \pm 2.6$, and $39.1 \pm 3.7 \mathrm{~mm}$, respectively. The mean \pm SD distances from the proximal epiphysis to the entry point of the nutrient artery into the second, third, and fourth metatarsals in the coronal plane were $23.8 \pm 4.7,25.8 \pm 4.3$, and $25.0 \pm 3.2 \mathrm{~mm}$, respectively.
\end{abstract}

Conclusions: Distal metatarsal osteotomies might be safer than shaft or proximal osteotomy to avoid disruption of the nutrient artery, leading to delayed consolidation of the osteotomy and nonunion.

Keywords: Lesser metatarsal, Nutrient artery, Osteotomy, Cadaver

\section{Background}

Osteotomies of the lesser metatarsals are used to treat a variety of pathologies of the foot, including metatarsalgia and metatarsophalangeal subluxation or dislocation [1]. Many osteotomy techniques have been described to shorten or elevate the lesser metatarsals, including oblique shaft osteotomy [2, 3], segmental midshaft osteotomy [4, 5], and proximal metatarsal osteotomy [6-9].

\footnotetext{
* Correspondence: i.tonogai@tokushima-u.ac.jp

${ }^{1}$ Department of Orthopedics, Institute of Biomedical Science, Tokushima University Graduate School, 3-18-15 Kuramoto, Tokushima 770-8503, Japan Full list of author information is available at the end of the article
}

Complications following osteotomy of the lesser metatarsals, which include nonunion and delayed union [10], have been attributed to iatrogenic disruption of the blood supply $[11,12]$. DeSandis et al. reported a nonunion rate of $6.6 \%$ after a mean 12.9 months of follow-up after shaft osteotomy of a lesser metatarsal [1], while Galluch et al. reported that the nonunion rate after lesser metatarsal shaft osteotomy was 0.8\% [5]. Spence et al. reported that only $24 \%$ of patients achieved bony union and the remaining $76 \%$ were considered to have nonunion after proximal osteotomy of a lesser metatarsal [4], while Lee et al. reported 2 cases of

(c) The Author(s). 2018 Open Access This article is distributed under the terms of the Creative Commons Attribution 4.0 International License (http://creativecommons.org/licenses/by/4.0/), which permits unrestricted use, distribution, and 
a
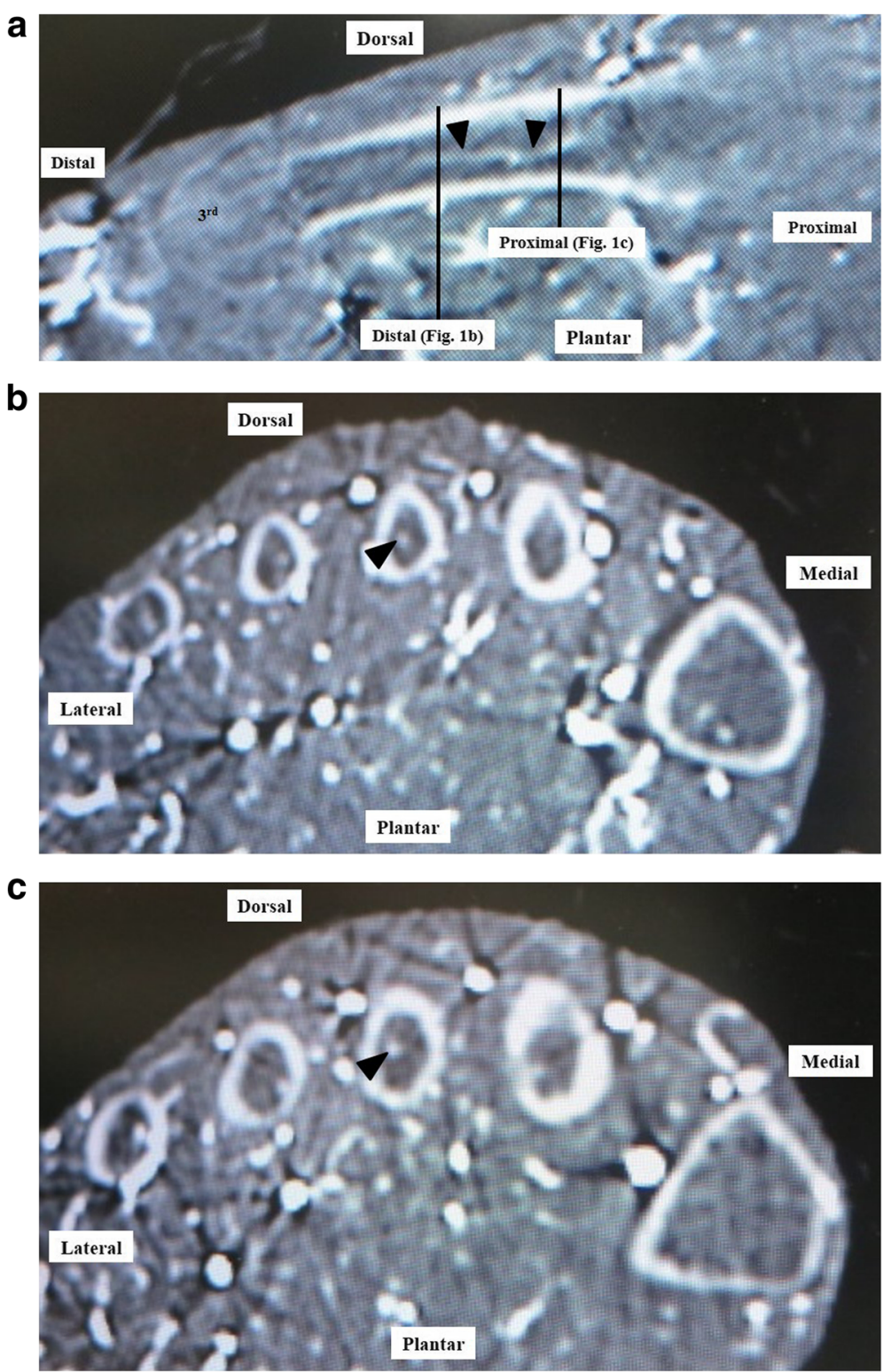

Fig. 1 Enhanced CT images showing the nutrient artery course after entering the lesser metatarsal. The nutrient artery runs within the medullary canal distally and proximally in the sagittal plane (a) and distally (b) and proximally (c) in the axial plane. The arrow head indicates the nutrient artery

Table 1 Measurement parameters of nutrient artery entry points of the lesser metatarsals on CT
CT axial plane
(1) Distances from the dorsal tangential plane to the points of entry of the nutrient arteries into the second, third, and fourth
metatarsals
(2) Distances from the plantar tangential plane to the points of entry of the nutrient arteries into the second, third, and fourth metatarsals plane
(4) Distances from the proximal epiphysis to the points of entry of the nutrient arteries into the second, third and fourth metatarsals
CT coronal (3) Distances from the distal epiphysis to the points of entry of the nutrient arteries into the second, third and fourth metatarsals 
delayed union and 1 of nonunion in $85 \mathrm{ft}$ (in 65 consecutive patients) that underwent proximal osteotomy of a lesser metatarsal [13].

Nonunion and delayed union of a lesser metatarsal may be related to disruption of the blood supply and has prompted recommendations to restrict the use of osteotomy. We have previously reported the point at which the nutrient artery enters the fifth lesser metatarsal [14], and the points at which the nutrient arteries enter the second, third, and fourth metatarsals have been discussed in a few reports $[11,12,15]$. However, there have been few studies with detailed description of the entry point of the nutrient artery into the lesser metatarsal.

The aims of this fresh cadaveric study were to identify the points at which nutrient arteries enter the second, third, and fourth metatarsals on axial and coronal enhanced computed tomography (CT) scans and to identify measures that could help to prevent injury to these arteries during osteotomy of the lesser metatarsals.

\section{Methods}

This study was approved by the research board at our institution and included $21 \mathrm{ft}$ of 21 fresh cadavers (male, $n=10$; female, $n=11$; mean age 78.6 years [range $48-$ 100] at the time of death). Cadavers with a history or signs of previous ankle trauma or surgery, congenital or developmental deformity, or inflammatory arthritis were excluded.

The vessels were flushed with warm normal saline solution through a plastic catheter placed in the external iliac artery. Barium sulfate suspension (Barytester, Fushimi Pharmaceutical Co., Inc., Marugame, Japan) was then injected into the external iliac artery with application of firm manual pressure as described in our previous reports [16-18]. Enhanced multi-slice computed tomography (CT) images (Somatom Emotion 16, Siemens Healthcare, Erlangen, Germany) of the lower extremities were obtained in 1.0-mm-thick axial slices. Coronal and axial images were reviewed at bone window setting (window, 2200; level, 200).

We confirmed the continuity of each nutrient artery after it entered the second, third, or fourth metatarsal. The nutrient artery divides into distal and proximal branches $[12,15]$, so we also confirmed that it ran distally and proximally within the medullary canal (Fig. 1a-c). As outlined in Table 1, the following parameters were measured: (1) the distance from the dorsal plane parallel to a line between the most plantar point of the first metatarsal (point A) and fifth metatarsal (point B) to the point of entry of the nutrient artery into the lesser metatarsal in the axial plane (Fig. 2a); (2) the distance from a line between the most plantar point of the first metatarsal (point

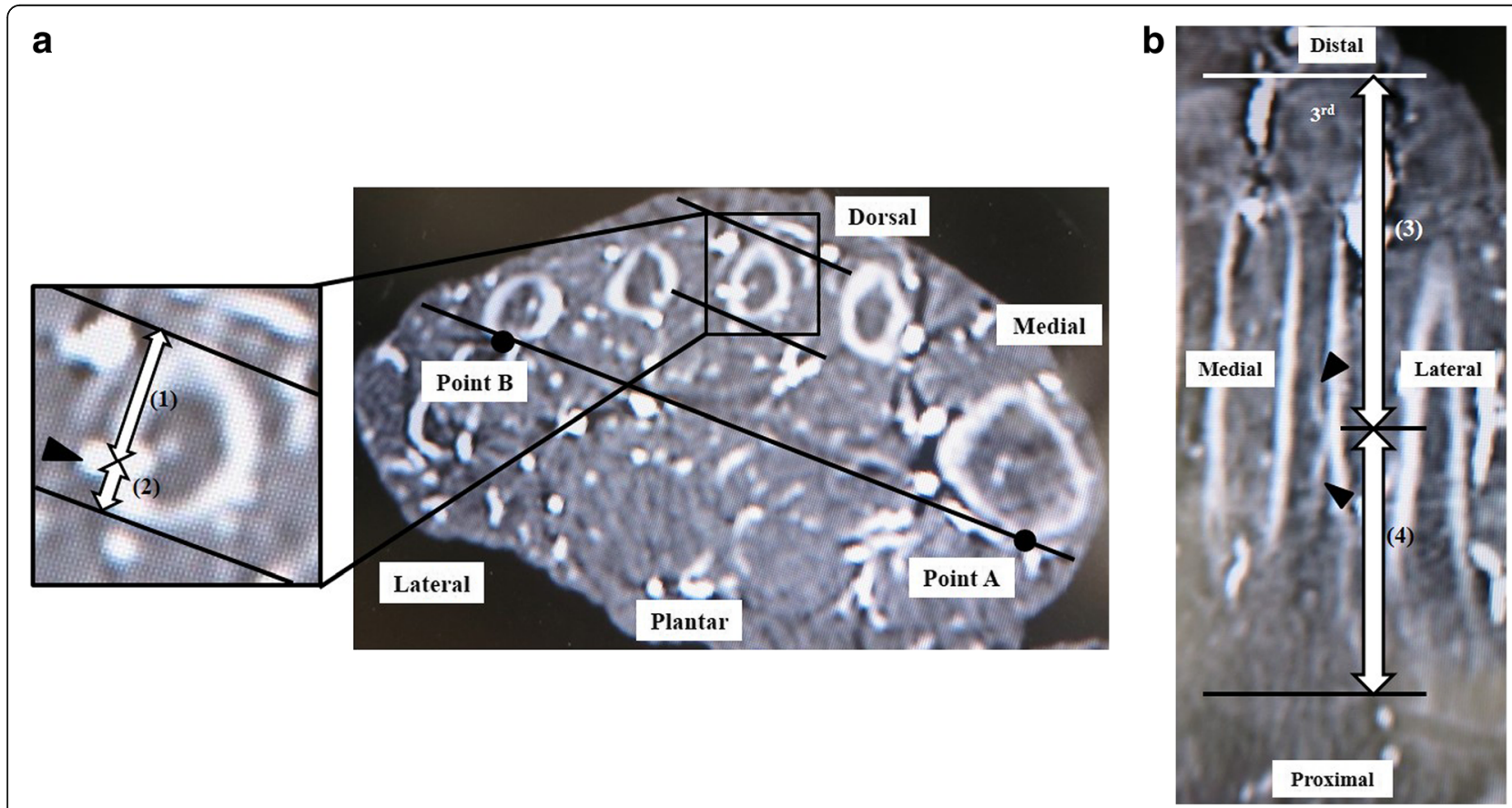

Fig. 2 Enhanced CT images showing nutrient artery parameters in relation to the lesser metatarsals. a Distance from the dorsal plane parallel to a line between the most plantar point of the first metatarsal (point A) and fifth metatarsal (point B) to the point of entry of the nutrient artery into the lesser metatarsal (1) and the distance from a line between the most plantar point of the first metatarsal (point A) and fifth metatarsal (point B) to the point of entry of the nutrient artery into the lesser metatarsal (2) in the axial plane. b Distance from the distal epiphysis to the point of entry of the nutrient artery into the lesser metatarsal (3), the distance from the proximal epiphysis to the point of entry of the nutrient artery into the lesser metatarsal (4) in the coronal plane. The arrow head indicates the nutrient artery 


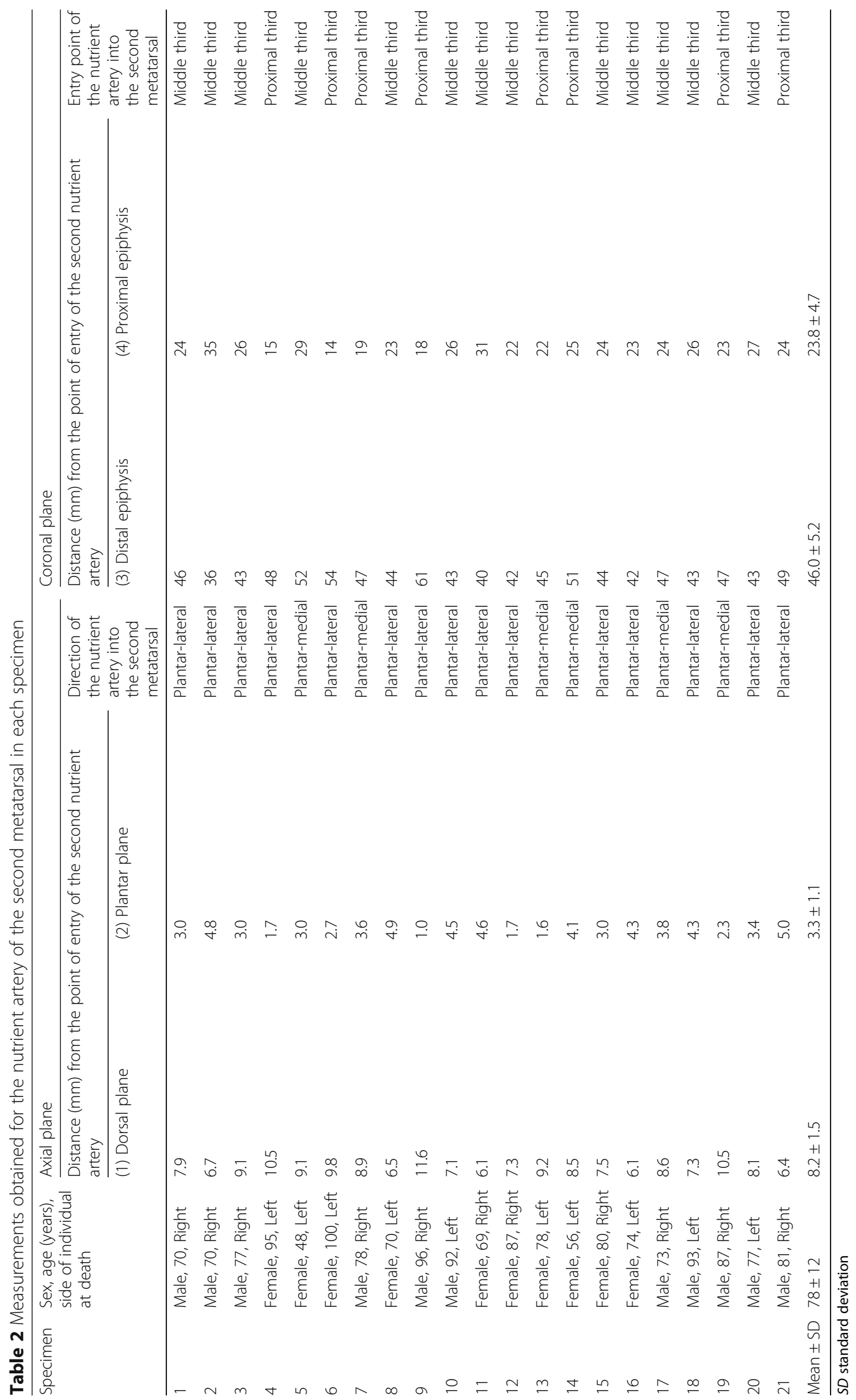




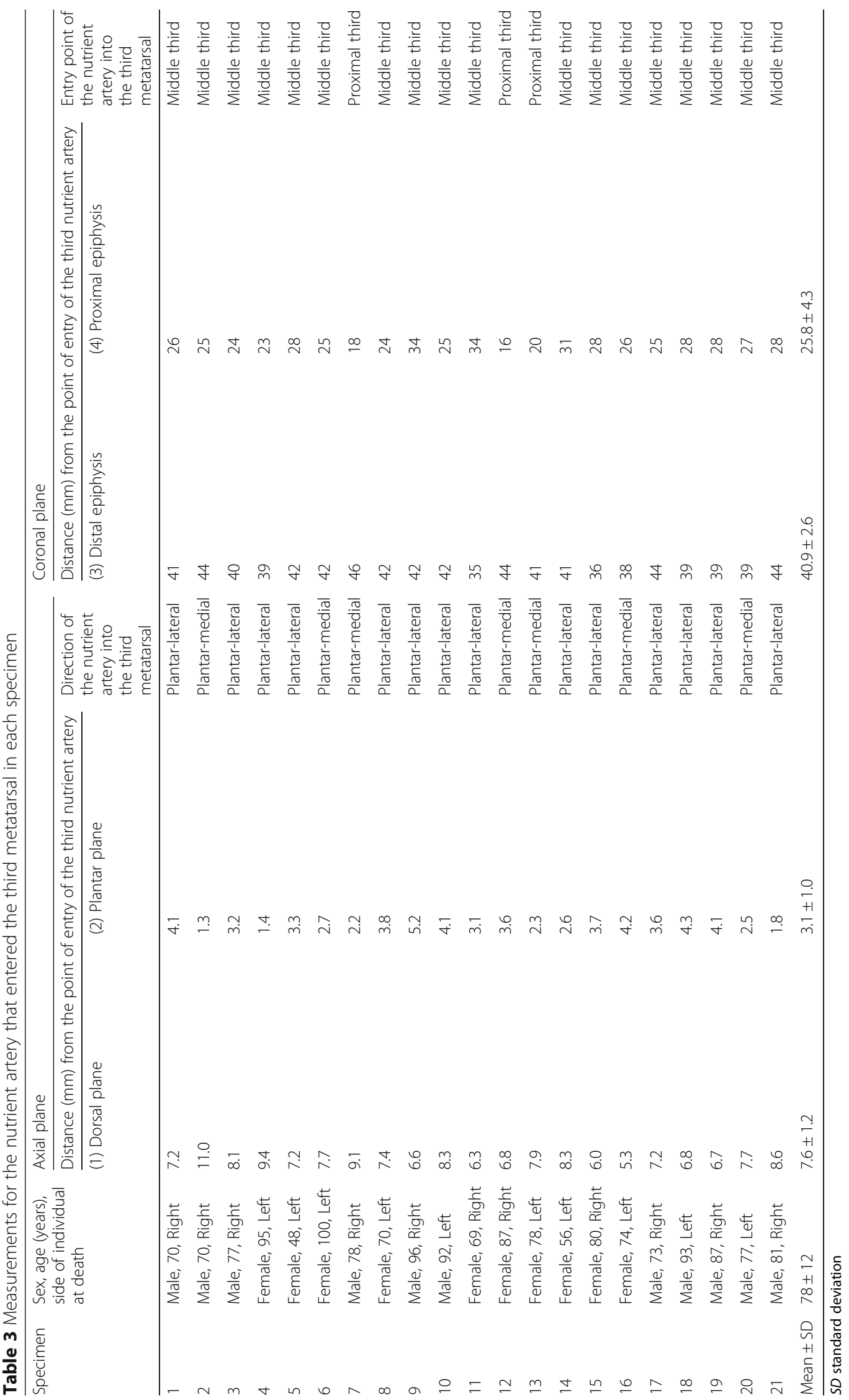


Table 4 Measurements for the nutrient artery that entered the fourth metatarsal in each specimen

\begin{tabular}{|c|c|c|c|c|c|c|c|}
\hline \multirow[t]{3}{*}{ Specimen } & \multirow{3}{*}{$\begin{array}{l}\text { Sex, age (years), } \\
\text { side of individual } \\
\text { at death }\end{array}$} & \multicolumn{3}{|l|}{ Axial plane } & \multicolumn{3}{|l|}{ Coronal plane } \\
\hline & & \multicolumn{2}{|c|}{$\begin{array}{l}\text { Distance }(\mathrm{mm}) \text { from entry point of } \\
\text { nutrient artery to }\end{array}$} & \multirow{2}{*}{$\begin{array}{l}\text { Direction of } \\
\text { nutrient artery } \\
\text { into fourth } \\
\text { metatarsal }\end{array}$} & \multicolumn{2}{|c|}{$\begin{array}{l}\text { Distance }(\mathrm{mm}) \text { from entry point of the fourth } \\
\text { nutrient artery to }\end{array}$} & \multirow{2}{*}{$\begin{array}{l}\text { Entry point of } \\
\text { nutrient } \\
\text { artery into } \\
\text { fourth } \\
\text { metatarsal }\end{array}$} \\
\hline & & (1) Dorsal plane & (2) Plantar plane & & (3) Distal epiphysis & (4) Proximal epiphysis & \\
\hline 1 & Male, 70, Right & 9.5 & 2.2 & Plantar-medial & 38 & 26 & Middle third \\
\hline 2 & Male, 70, Right & 10.1 & 1.2 & Plantar-medial & 36 & 26 & Middle third \\
\hline 3 & Male, 77, Right & 10.0 & 1.0 & Plantar-medial & 39 & 23 & Middle third \\
\hline 4 & Female, 95, Left & 8.7 & 1.3 & Plantar-medial & 33 & 28 & Middle third \\
\hline 5 & Female, 48, Left & 7.2 & 3.0 & Plantar-lateral & 39 & 28 & Middle third \\
\hline 6 & Female, 100, Left & 6.5 & 3.0 & Plantar-medial & 38 & 28 & Middle third \\
\hline 7 & Male, 78, Right & 6.0 & 4.1 & Plantar-medial & 39 & 23 & Middle third \\
\hline 8 & Female, 70, Left & 5.5 & 4.9 & Plantar-lateral & 43 & 20 & Proximal third \\
\hline 9 & Male, 96, Right & 10.6 & 1.0 & Plantar-medial & 48 & 27 & Middle third \\
\hline 10 & Male, 92, Left & 9.2 & 3.3 & Plantar-medial & 41 & 24 & Middle third \\
\hline 11 & Female, 69, Right & 6.4 & 6.2 & Plantar-medial & 39 & 29 & Middle third \\
\hline 12 & Female, 87, Right & 8.1 & 3.5 & Plantar-medial & 40 & 19 & Proximal third \\
\hline 13 & Female, 78, Left & 6.7 & 1.7 & Plantar-lateral & 35 & 25 & Middle third \\
\hline 14 & Female, 56, Left & 6.9 & 3.5 & Plantar-lateral & 33 & 32 & Middle third \\
\hline 15 & Female, 80 , Right & 6.0 & 3.1 & Plantar-lateral & 38 & 24 & Middle third \\
\hline 16 & Female, 74, Left & 6.2 & 2.8 & Plantar-medial & 42 & 20 & Proximal third \\
\hline 17 & Male, 73, Right & 9.1 & 2.7 & Plantar-lateral & 44 & 21 & Proximal third \\
\hline 18 & Male, 93, Left & 7.3 & 2.8 & Plantar-medial & 39 & 26 & Middle third \\
\hline 19 & Male, 87, Right & 8.0 & 2.4 & Plantar-medial & 38 & 26 & Middle third \\
\hline 20 & Male, 77, Left & 5.7 & 2.8 & Plantar-medial & 35 & 27 & Middle third \\
\hline 21 & Male, 81, Right & 7.1 & 2.9 & Plantar-lateral & 46 & 24 & Middle third \\
\hline Mean \pm SD & $78 \pm 12$ & $7.6 \pm 1.5$ & $2.8 \pm 1.2$ & & $39.1 \pm 3.7$ & $25.0 \pm 3.2$ & \\
\hline
\end{tabular}
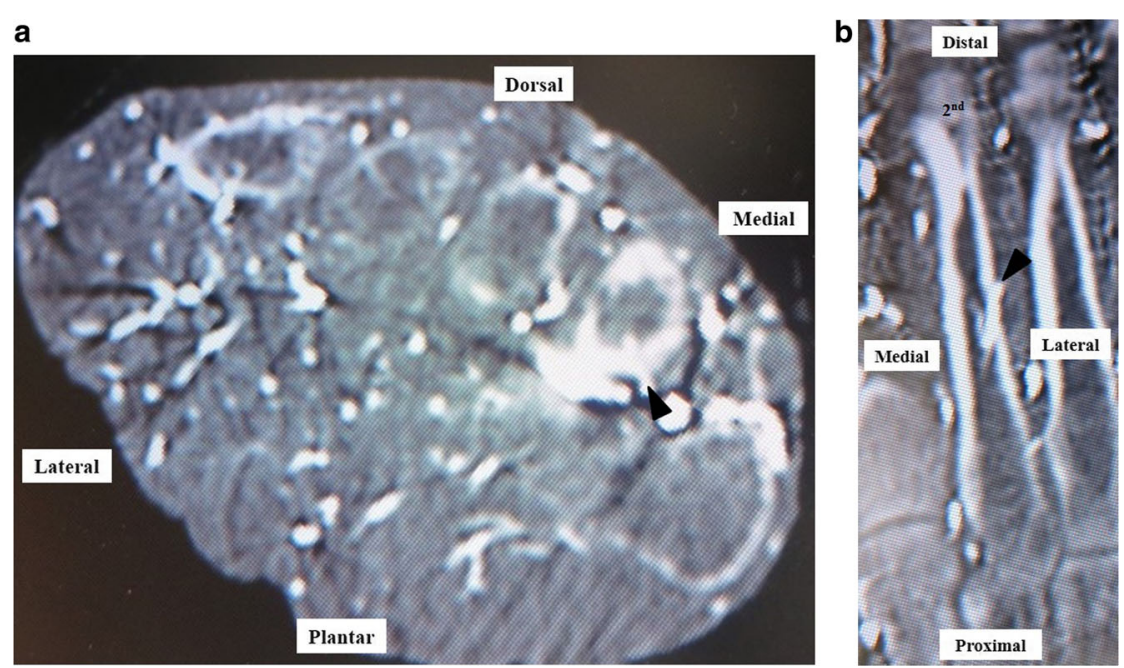

Fig. 3 Enhanced CT images showing the nutrient artery entering the lesser metatarsal medially (a) In the axial plane and, (b) in the coronal plane. The arrow head indicates the nutrient artery 
A) and fifth metatarsal (point B) to the point of entry of the nutrient artery into the lesser metatarsal in the axial plane (Fig. 2a); (3) the distance from the distal epiphysis to the point of entry of the nutrient artery into the lesser metatarsal in the coronal plane (Fig. 2b); and (4) the distance from the proximal epiphysis to the point of entry of the nutrient artery in the coronal plane (Fig. 2b). Measurements were made in triplicate by two independent orthopedic surgeons (F.H. and K.S) who were blinded to the purpose of the study, and the first author (I.T.) did not results to measurement. Mean values were calculated. Data are expressed as mean \pm standard deviation (SD).

\section{Results}

A summary of the results is shown in Tables 2, 3 and 4 . The mean \pm standard deviation (SD) distances from the dorsal plane of the second, third, and fourth metatarsals to the points of entry of the nutrient artery in the axial plane (1) were $8.2 \pm 1.5 \mathrm{~mm}$ (range 6.1-11.6), $7.6 \pm$ $1.2 \mathrm{~mm}$ (range 6.0-11.0), and 7.6 $\pm 1.5 \mathrm{~mm}$ (range 5.5$10.6)$, respectively. The mean $\pm(\mathrm{SD})$ distances from the plantar plane of the second, third, and fourth metatarsals to the points of entry of the nutrient artery in the axial plane (2) were $3.3 \pm 1.1 \mathrm{~mm}$ (range 1.0-5.0), $3.1 \pm 1.0 \mathrm{~mm}$ (range 1.4-5.2), and $2.8 \pm 1.2 \mathrm{~mm}$ (range 1.0-6.2), respectively. All nutrient arteries entered the lesser metatarsals from the plantar aspect, but some entered via the lateral aspect and others via the medial aspect (Fig. 3a, b). The nutrient arteries supplying the second, third, and fourth metatarsals entered from the lateral plantar direction in 15/21 (71.4\%), 14/21 (66.7\%), and 7/21 (33.3\%) specimens, respectively.

All nutrient arteries entered from the distal direction obliquely in the coronal plane (Fig. 4). The mean \pm (SD) distances from the distal epiphysis to the points of entry of the nutrient artery into the second, third, and fourth metatarsals in the coronal plane (3) were $46.0 \pm 5.2 \mathrm{~mm}$ (range 36-61), 40.9 $\pm 2.6 \mathrm{~mm}$ (range 35-46), and $39.1 \pm$ $3.7 \mathrm{~mm}$ (range 33-48), respectively. The mean \pm (SD) distances from the proximal epiphysis to the entry points of the nutrient artery into the second, third, and fourth metatarsals in the coronal plane (4) were $23.8 \pm 4.7 \mathrm{~mm}$ (range 15-35), 25.8 $\pm 4.3 \mathrm{~mm}$ (range 16-34), and 25.0 \pm $3.2 \mathrm{~mm}$ (range 19-32). Most of the nutrient arteries entered the second, third, and fourth metatarsals between the middle third and the proximal third, but some entered very near to the midpoint of the metatarsal (specimen 2 in the second metatarsal, specimen 11 in the third metatarsal, and specimen 14 in the fourth metatarsal; Fig. 4). The nutrient arteries entered the second, third, and fourth metatarsals at the level of the middle third in 13/21 (61.9\%), 18/21 (85.7\%), and 17/21 (81.0\%) of the specimens, respectively. When the nutrient artery entered the second, third, or fourth metatarsal at the level of the

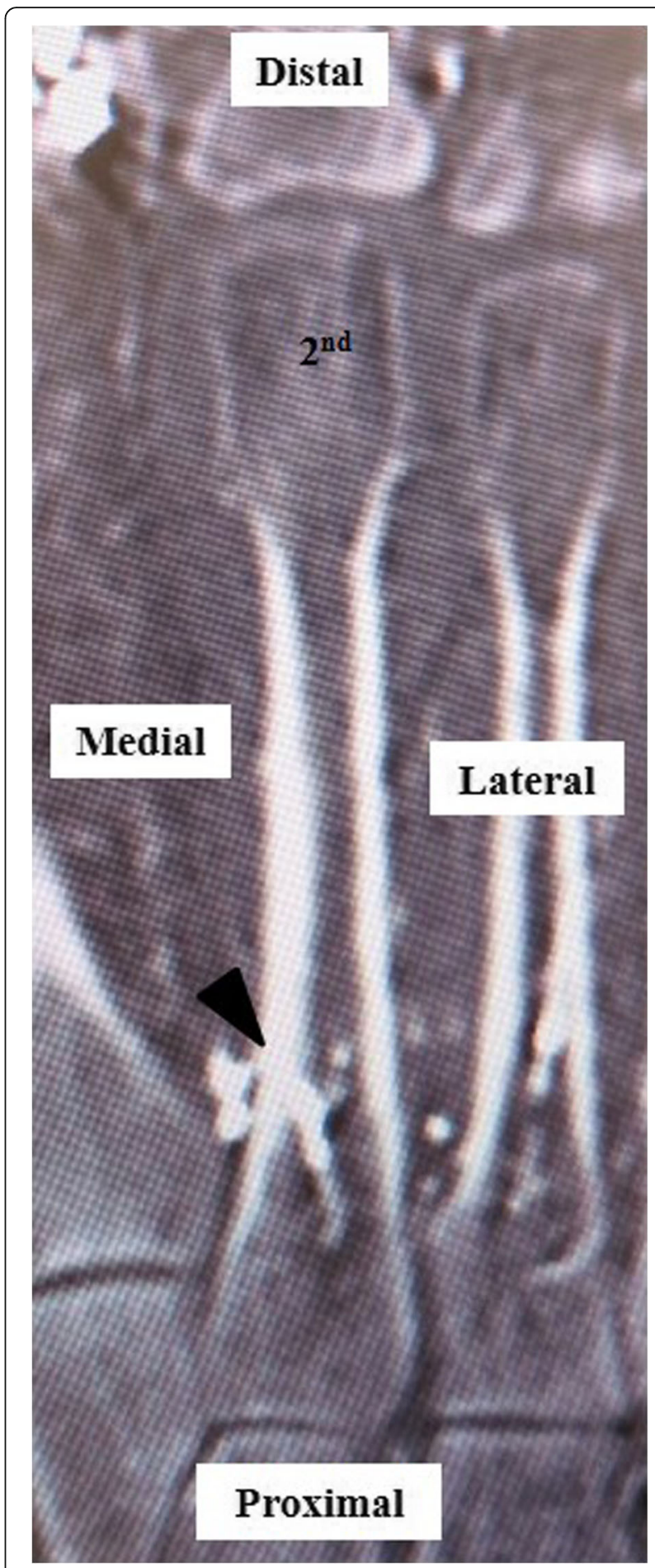

Fig. 4 Enhanced CT showing the nutrient artery entering the lesser metatarsal near the mid-point. The nutrient artery enters the lesser metatarsal near the mid-point from a distal direction laterally and obliquely in the coronal plane. The arrow head indicates the nutrient artery 


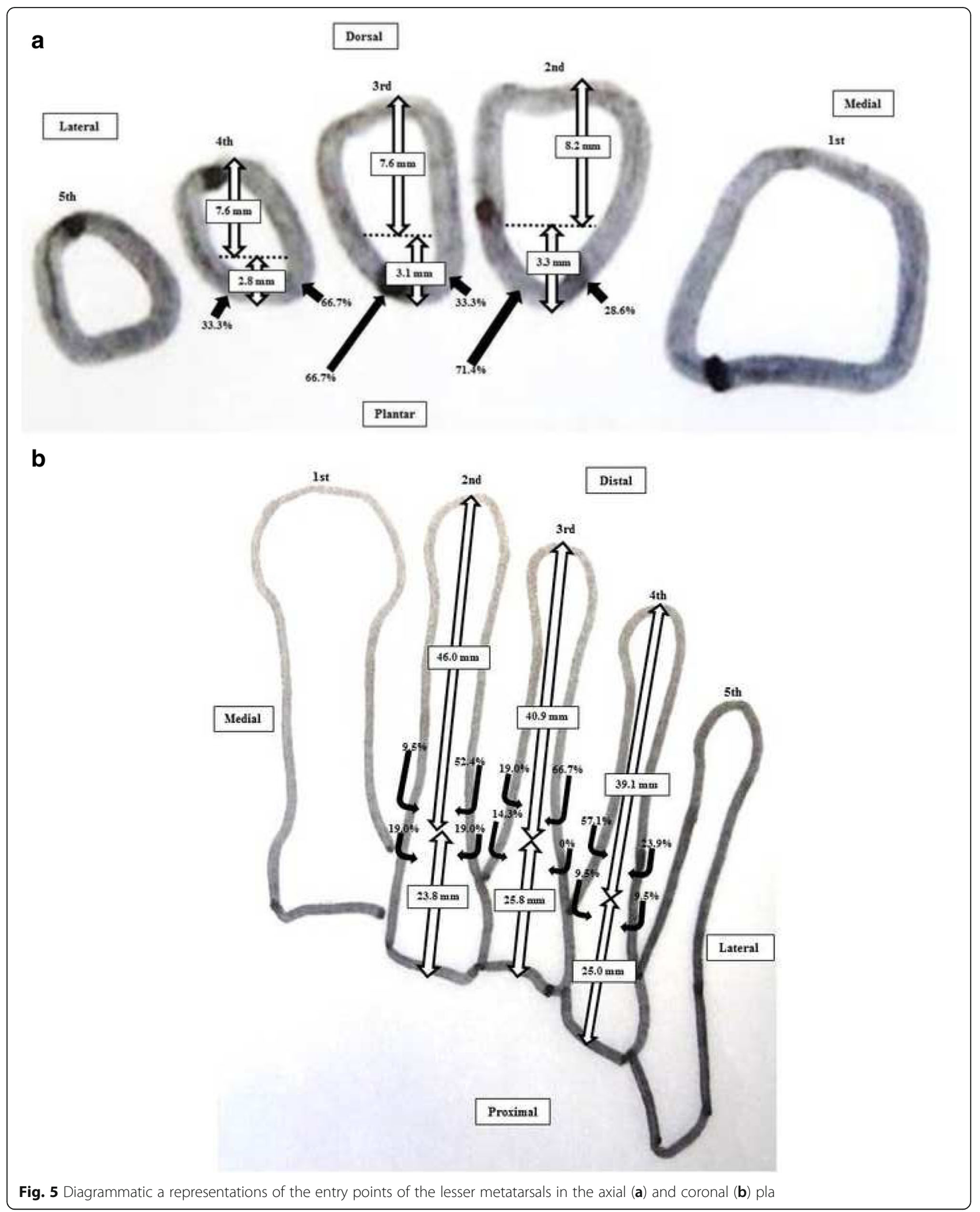


middle third, the entry point was just proximal to the middle point of the metatarsal.

\section{Discussion}

This study shows that the nutrient arteries do not enter into the second, third, or fourth metatarsal from a designated direction, that is, lateral or medial, and that the nutrient arteries supplying the second, third, and fourth metatarsals enter at the middle third (just proximal to the midpoint of the metatarsal) or proximal third distally from a medial or lateral plantar direction, as diagrammatic representions show (Fig. 5a, b). Our findings might imply that care is needed on both sides when performing an osteotomy involving a lesser metatarsal, and that the widely practiced distal metatarsal osteotomies, such as Weil and Schwartz, should be considered than shaft or proximal osteotomy to avoid disruption of the nutrient artery, leading to delayed consolidation of the osteotomy and nonunion.

Petersen et al. [12] and Sarrafian [15] have reported that a nutrient artery enters the second, third, or fourth metatarsal by penetrating the lateral diaphysis. In the present study, although many nutrient arteries entered the lesser metatarsals via the lateral aspect (second metatarsal, $71.4 \%$; third metatarsal, $66.7 \%$; fourth metatarsal, 33.3\%), many also entered via the medial aspect. To our knowledge, this is the first fresh cadaveric study to show on enhanced CT that the entry point of the nutrient artery into a lesser metatarsal is sometimes from the medial direction.

Petersen et al. [11] and Rath et al. [12] reported that the nutrient artery transverses the cortex of the metatarsal in a distal direction in the coronal plane. In this study, the nutrient artery entered the lesser metatarsal obliquely in a distal direction in all cases. Moreover, Sarrafian reported that the pattern of entry of the nutrient artery into the second, third, and fourth metatarsals was similar [15], and our findings were consistent with that report.

Sarrafian also reported that the nutrient artery penetrates the lateral surface near the base in the coronal plane [15]. However, Petersen et al. reported that the nutrient artery enters the bone in the middle of the diaphysis (midshaft) [11]. In our study, some nutrient arteries entered the lesser metatarsal at the level of the middle third (just proximal to midpoint of the metatarsal) and others at the level of the proximal third. This variation might reflect ethnic differences in foot and ankle anatomy.

Our study had several limitations, in particular the small number of specimens used, which is inevitable because of the limited availability of fresh-frozen cadavers in Japan. Another limitation is that the intraosseous blood supply provided by the periosteal plexus and metaphyseal and epiphyseal vessels via anastomosis was not assessed, given that these arteries also supply blood to the lesser metatarsals.
No intraosseous arteries smaller than the nutrient arteries were identified in this study.

\section{Conclusions}

In conclusion, this study has shown that the nutrient arteries supplying the second, third, and fourth metatarsals enter at the middle third (just proximal to the midpoint of the metatarsal) or proximal third distally from a medial or lateral plantar direction. The point at which the nutrient artery enters a lesser metatarsal is important when performing osteotomy. Although shaft and proximal osteotomies are useful, they may interrupt blood flow in the nutrient artery and cause delayed union or nonunion. The widely practiced distal metatarsal osteotomies might be safaer than shaft or proximal osteotomy.

\section{Abbreviations \\ CT: Computed tomography; SD: Standard deviation}

\section{Funding}

This study was supported in part by a Grant-in-Aid for Scientific Research from the Ministry of Education, Culture, Sports, Science and Technology of Japan (17 K16694 to I.T.).

\section{Availability of data and materials}

All data generated or analysed during this study are included in this published article (and its supplementary information files).

\section{Authors' contributions}

IT was responsible for this study, and managed this study. IT performed enhanced $\mathrm{CT}$ examinations for fresh cadavers. IT did not results to measurement. Dr. FH measured parametrers in obtained images. Dr. YT supervised the enhanced CT examinations of fresh cadavers by IT. Dr. KS also measured parametrers in obtained images. All authors read and approved the final manuscript.

\section{Ethics approval and consent to participate}

This study was approved by the research board of Tokushima University Hospital (reference no. 2258).

\section{Consent for publication \\ Not applicable.}

\section{Competing interests}

The authors declare that they have no competing interests.

\section{Publisher's Note}

Springer Nature remains neutral with regard to jurisdictional claims in published maps and institutional affiliations.

\section{Author details \\ ${ }^{1}$ Department of Orthopedics, Institute of Biomedical Science, Tokushima University Graduate School, 3-18-15 Kuramoto, Tokushima 770-8503, Japan. ${ }^{2}$ Department of Anatomy and Cell Biology, Institute of Biomedical Science, Tokushima University Graduate School, 3-18-15 Kuramoto, Tokushima 770-8503, Japan.}

Received: 2 July 2018 Accepted: 31 July 2018

Published online: 08 August 2018

\section{References}

1. DeSandis B, Ellis SJ, Levitsky M, O'Malley Q, Konin G, O'Malley MJ. Rate of union after segmental midshaft shortening osteotomy of the lesser metatarsals. Foot Ankle Int. 2015;36:1190-5. https://doi.org/10. $1177 / 1071100715585560$. 
2. Helal B. Metatarsal osteotomy for metatarsalgia. J Bone Joint Surg Br. 1975;57:187-92.

3. Helal B, Griess M. Telescoping osteotomy for pressure metatarsalgia. J Bone Joint Surg Br. 1984;66:213-7.

4. Spence KF, O'Connell SJ, Kenzora JE. Proximal metatarsal segmental resection: a treatment for intractable plantar keratosis. Orthopedics. 1990;13:741-7.

5. Galluch DB, Bohay DR, Anderson JG. Midshaft metatarsal segmental osteotomy with open reduction and internal fixation. Foot Ankle Int. 2007; 28:169-74. https://doi.org/10.3113/FAl.2007.0169.

6. Harper MC. Dorsal closing wedge metatarsal osteotomy: a trigonometric analysis. Foot Ankle. 1990;10:303-5.

7. Barouk LS. Forefoot reconstruction. 2nd ed. Paris: Springer Verlag; 2005.

8. Pearce CJ, Calder JD. Metatarsalgia: proximal metatarsal osteotomies. Foot Ankle Clin. 2011;16:597-608. https://doi.org/10.1016/j.fcl.2011.08.007.

9. Vafek EC, Lee S. Treatment of metatarsalgia with proximal osteotomies. Foot Ankle Clin. 2018;23:35-46. https://doi.org/10.1016/.jfl.2017.09.005.

10. Bellacosa RA, Pollak RA. Complications of lesser metatarsal surgery. Clin Podiatr Med Surg. 1991;8:383-97.

11. Petersen WJ, Lankes JM, Paulsen F, Hassenpflug J. The arterial supply of the lesser metatarsal heads: a vascular injections study in human cadavers. Foot Ankle Int. 2002;23:491-5. https://doi.org/10.1177/107110070202300604.

12. Rath B, Notermans HP, Franzen J, Knifka J, Walpert J, Frank D, Koebke J. The microvascular anatomy of the metatarsal bones: a plastination study. Surg Radiol Anat. 2009;31:271-7. https://doi.org/10.1007/s00276-008-0441-3.

13. Lee J, Kim J, Lee M, Chu I, Lee S, Gwak H. Morton's neuroma (interdigital neuralgia) treated with metatarsal sliding osteotomy. Indian J Orthop. 2017; 51:692-6. https://doi.org/10.4103/0019-5413.217678.

14. Tonogai I, Hayashi F, Tsuruo Y, Sairyo K. Direction and location of the nutrient artery to the fifth metatarsal at risk in osteotomy for bunionette. Foot Ankle Surg. 2017. https://doi.org/10.1016/j.fas.2017. 10.006. Epub ahead of print.

15. Sarrafian SK. Anatomy of the foot and ankle: descriptive, topographic, functional. 2nd ed. Philadelphia: Lippincott; 1993. p. 294-312, 319-21, 342-5.

16. Tonogai I, Wada K, Higashino K, Fukui Y, Sairyo K. Location and direction of the nutrient artery to the first metatarsal at risk in osteotomy for hallux valgus. Foot Ankle Surg. 2017. https://doi.org/10.1016/j.fas.2017.05.004. Epub ahead of print.

17. Tonogai I, Hayashi F, Tsuruo Y, Sairyo K. The distance between the anterior distal tibial edge and the anterior tibial artery in non-distracted and distracted ankle positions during anterior ankle arthroscope: a cadaveric study. Foot Ankle Int. 2018;39:113-8. https://doi.org/10.1177/ 1071100717732550

18. Tonogai I, Hayashi F, Tsuruo Y, Sairyo K. Examination of the origin and branching direction of the anterior medial malleolar artery from the anterior tibial artery to avoid pseudoaneurysm in anterior ankle arthroscopy: a cadaveric study. Foot Ankle Spec. 2018. https://doi.org/10.1177/ 1938640018768046. Epub ahead of print.

Ready to submit your research? Choose BMC and benefit from:

- fast, convenient online submission

- thorough peer review by experienced researchers in your field

- rapid publication on acceptance

- support for research data, including large and complex data types

- gold Open Access which fosters wider collaboration and increased citations

- maximum visibility for your research: over $100 \mathrm{M}$ website views per year

At BMC, research is always in progress.

Learn more biomedcentral.com/submissions 